Table 1. INHIBITION OF THE ENDOGRNOUS MFTABOLISM of Mycobracterium smegmatis BX PENICILLIN AND PENICILLIN-ISONIAZID COMBINATIONS

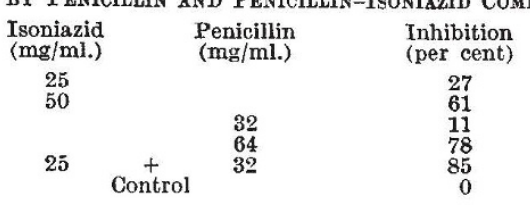

$M$. smegmatis is potentiated when they are combined. Relatively high concentrations of both ponicillin and isoniazid are required to produce the effects noted.

Pope ${ }^{6}$ demonstrated that relatively high concentrations of isoniazid are required to inhibit the endogenous metabolism of $M$. tuberculosis. Furthermore, she hypothesized that the primary site of antimycobacterial action of isoniazid is concerned with the synthosis of metabolites vital to the multiplication and proper functioning of the organism and that action of isoniazid on the catabolic processes is only of secondary importance. When extended to include the action of penicillin on $M$. smegmatis this hypothesis may apply to the present experiments.

F. M. K. Vaichulis

E. E. VICHER

M. V. NOVAK

Department of Microbiology,

University of Illinois College of Medicine, Chicago.

${ }^{2}$ Vaichulis, E. M. K., and Doll, J. P., Amer. Rev. Resp. Dis., 80, 262 (1959),

' Vaichulis, E. M. K., Vicher, E. E., and Novak, M. V., Amer. Rev. Resp. Dis.. 86, 744 (1962); also in preparation.

3 Vaichulis, E. M. K., Amer. Reo. Resp. Dis., 83, 121 (1961).

- Bernheim, F., J. Biol. Chem., 143, 383 (1942).

- Nasta, M., Pauneseo, E., and Georgesco, P., Ann. Inst. Pasteur, 99, 504 $(1960)$.

- Pope, H., Amer. Rev. Pulmonary Dis., 73, 735 (1956).

\section{Lethal Action by an Acetobacter on Yeasts}

IT has been found that a recently isolated strain of Acetobacter caused yeasts to die when both organisms wero present in a nutrient medium in full screw-capped bottles. In a typical test full McCartney bottles of beer were inoculated with $5 \times 10^{5}$ cells per ml. of Saccharomyces cerevisiae and amounts of a suspension of a washed culture of Acetobacter were added to different bottles to give counts of from 0 to $50 \times 10^{5}$ cells per ml. The numbers of viable yeasts were determined daily by methylene blue staining during incubation at $25^{\circ}$, with the results shown in Fig. 1.

When no Acetobacter were present the yeast followed the normal growth curve for these conditions as in Fig. Ia. When the ratio of Acetobacter cells to yeast cells was $1: 1$ very little yeast growth occurred, as in Fig. $1 b$. When this ratio was $3: 1$ no growth took place and the yeast cells began to die off after 5 days, as in Fig. 1c. When the ratio was 10 Acetobacter to 1 yeast cell the yeasts were all dead after 3 days, as in Fig. 1d. During incubation for 10 days there was vory little fall in specific gravity of the medium in case $b$ and none at all in $c$ and $d$, whereas in $a$ the specific gravity fell to an extent indicating that the available carbohydrate had been fermented. In these experiments there was no rise in acidity due to acetic acid formation by the bacteria and the numbers of viablo Acetobacter fell during incubation, for example. from $15 \times 10^{5}$ cells per ml, at start to $8 \times 10^{3}$ cells per ml. after 10 days. In other experiments of this type it was shown that the ratios of bacteria to veast required to kill the yeast cells depended on the media and on other experimental conditions. The anti-yeast action was loss marked in synthetic media than in beer and no lethal action took place when the yeasts and Acetobacter were incubated together in a $p \mathrm{H} 5$ phosphate buffer solution.

A similar lethal action of Acetobacter was observed on yeasts from the genera Pichia, Schizosaccharomyces, Zygosaccharomyces, Torula, Candida. and Brettanomyces,

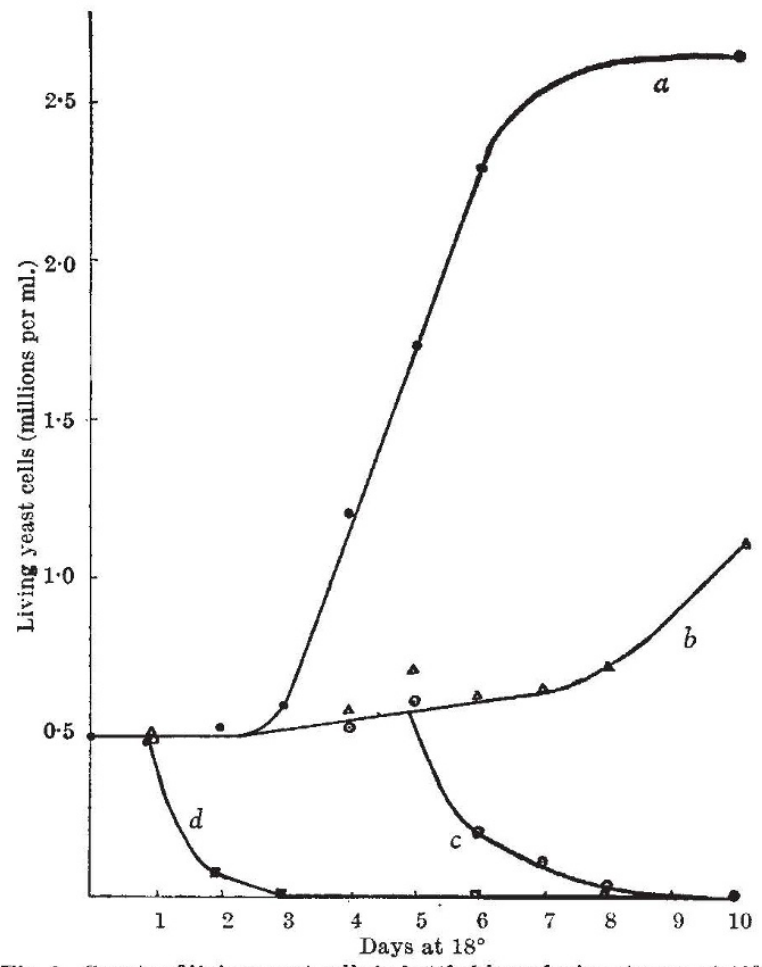

Fig. 1. Counts of living yeast cells in bottled beer during storage at $18^{\circ}$ $a$, Control, without any addition; $b, \Delta$, with one Acetobacter added per yeast cell; $c$, $\odot$, with three Acetobacter added per yeast cell;

as well as on other species in the genus Saccharomyces. Some bacteria were also killed by the Acetobacter, for example, Lactobacillus pastorianus was killed by the presence of as little as one Acetobacter por 1,000 Lactobacilli in bottled beer. The growth of a strict anaerobe, Clostridia perfringins, was not inhibited by the presence of Acetobacter. Lethal or inhibitory action was not observed against any organism under aerobic conditions, except such action as could be completely explained by the presence of acetic acid produced under these conditions by the Acetobacter.

The strain of Acetobacter used for these experiments was classified according to Frateur's system ${ }^{1}$ and was found to correspond most nearly to Acetobacter mesoxydans. Pure cultures of Acetobacter mesoxydans and of A. aceti, A. xylinum, A. lovaniense, A. rancens and Acetomonas suboxydans were received from the National Collection of Industrial Bacteria and their ability to kill yeasts under the test conditions was examined. All were found to be without lethal action, so that this property appeared to be confined to specific strains.

Bacteria which had been destroyed by heat treatment, by treatment with chloroform, or by ultra-violet light were inactive. Bacteria which had been disintegrated by shaking with glass beads in a Braun disintegrator were also without activity.

So far as is known, this is the first record of an antagonism between Acetobacter and other organisms under similar conditions. Escherichia coli has beon shown to be inhibitory to Candida albicans $s^{2}$ a Pseudomonas of marine origin had selective ability to inhibit yeast growth ${ }^{3}$; some strains of Pseudomonas aeruginosa wero shown to inhibit the growth of Candida albicans and other pathogenic fungi ${ }^{4}$; and a number of yeasts, including one Saccharomyces spocies, were inhibited by various soil bacteria including Aeromonas, Pseudomonas, Achromobacter, Aerobacter, Serratia and Bacillus ${ }^{5}$. Theso antagonisms were all demonstrated under aerobic conditions and all appeared to be due to production of antibiotic by the bacteria. They are, therefore, clearly different in type from the inhibition 
of yeasts by washed cultures of Acetobacter under conditions in which no bacterial growth took place.

We thank Dr. A. K. Mills for his advice.

$$
\text { R. B. Gillimland }
$$

$$
\text { J. P. LaceY }
$$

Arthur Guinness Son and Co. (Dublin), Ltd.,

$$
\text { St. James's Gate, Dublin, } 8 .
$$

${ }^{1}$ Frateur, J., La Cellule, 53, 287 (1950).

${ }^{2}$ Rosebury, T., Gale, D., and Taylor, F. D., J. Bacteriol., 67, 135 (1954).

suck, J. D., Ahearn, D. G., Roth, F. J., and Meyers, S. P., J. Bact., 85, 1132 (1963).

- Klite, P. D., and Gale, G. R., Antibiot. Chemotherapy, 11, 256 (1961).

5 di Menna, M. E., J. Gen. Microbiol., 27, 249 (1962).

\section{GENETICS}

\section{Frequency of Glucose-6-phosphate Dehydro- genase Deficiency, Red-Green Colour Blindness and $\mathbf{X g a}$ Blood-group among Chamorros}

Progressive fatal neurological diseases, such as amyotrophic lateral sclerosis, occur with exceptionally high incidence in the indigenous population of Guam and the other Mariana Islands in the Western Pacific. Recent investigations indicate that these neurological problems are not limited to the Chamorros, the indigenous population of the Marianas ${ }^{1,2}$. Since extensive pedigree and epidemiological data revealed no single genetic defect which might reasonably account for such abnormalities, ancestral relationships among different aboriginal populations of the Western Pacific are being examined. If the ancestry of these groups can be defined in terms of several common genetic markers, then a comparison of the incidence of amyotrophic lateral sclerosis, Parkinsonism-dementia or other neurological diseases occurring within these groups might facilitate the separation of genetic and non-genetic disease-producing factors. This communication reports the results of a preliminary survey for three sex-linked traits : glucose-6-phosphate dehydrogenase (G-6-PD) deficiency, red-green colour blindness and Xga blood-group in Chamorro males. The results are summarized in Table 1.

The sample tested were males attending the only two high schools on the Island. Compulsory education of all Chamorros ensured random representation of natives from all parts of Guam by such a sampling technique. No sibship in the sample was represented by more than one sibling.

The G-6-PD determinations were carried out by the method of Motulsky ${ }^{3}$. Of 246 students tested, the blood from one $(0 \cdot 4$ per cent) had a decolorization timo of greater than $3 \mathrm{~h}$ on duplicate determinations. This frequency is the same which Blumberg et al. found in other population isolates in Micronesia. These results should also be compared to the frequency of G-6-PD deficiency in Carolinians from four islands in Micronesia: Angour, 9 per cent; Koror, 8 per cent; Ifalik, 6 per cent; Ulithi, 0 per cents. There is no malaria in Guam. Table 1. FREQUENCY OF G-6-PD DEFICIENCY, RED-GREEN COLOUR

$\begin{array}{ccc}\begin{array}{c}\text { No. of males } \\ \text { tested }\end{array} & \text { No. positive } & \begin{array}{c}\text { Percentage } \\ \text { positive }\end{array} \\ 246 & 1 & 0 \cdot 4 \\ 246 & 8 & 3 \cdot 3 \\ 109 & 71 & 65\end{array}$

G-6-PD deflciency $\mathrm{Xga}$ blood-group

109 65

246 students were tested for red-green colour blindness with American Optical Pseudo-isochromatic Plates. $8(3 \cdot 3$ per cent) were colour-blind. About 4 per cent of Filipinos ${ }^{\theta}$ and Japanese ${ }^{7}$ are colour-blind, whereas in the United States and in Europe about 8 per cent of the male population have some type of colour-blindness.

109 Chamorro boys were tested for Xga blood-group by the technique of Mann et al. ${ }^{8}$. 71 (65 per cent) were positive. This result does not differ from the frequency of the Xga gene in Caucasians (62 per cent) and in Negroes (59 per cent).
We thank the Guam Board of Education and Mr. Ronald O. Sime, principal of Tumon and Washington High Schools, for their help in carrying out our field investigations. We also thank Drs. J. D. Mann and R. A. Cahan for supplying the X $\mathrm{g}^{\mathrm{a}}$ anti-serum.

Chris C. Plato

Manuer T. Criz

L. T. KuRLAND

National Institute of Neurological

Diseases and Blindness.

National Institutes of Health.

Bethesda, Maryland.

Kurland, L. T., in The Genetics of Migrant and Isolate Populations, edit. by Goldschmidt, E., 195 (Williams and Wilkins Co., New York, 1963). ${ }^{2}$ Mathai, K. V. (personal communication, June 1963).

${ }^{3}$ Motulsky, A., in Proc. Conf. Genetic Polymorphisms and Geographic Variations in Disease, edit. by Blumberg, B. S., 165 (Grune and Stratton, New York, 1961)

- Blumberg, B. S., quoted in Motulsky, A., loc. cit., 168.

- Kidson, C., and Gajdusek, D. C., Austral. J. Sci., 25, 61 (1962).

- Nolasco, J. B., and Rodil, D., Arch. Ophthal., 41, 20 (1949).

7 Post, R., Eugenics Quart., 9, 131 (1962).

Mann, J. D., Cahan, A., Gelb, A. G., Fisher, N., Hamper, J., Trippet, P., Sanger, R., and Race, R. R., Lancet, it, 8 (1962).

\section{VIROLOGY}

\section{Relationship between Adenoviruses and Canine Hepatitis Virus}

$I_{T}$ was shown by Kapsenberg ${ }^{1}$ and Heller and Salenstedt ${ }^{2}$ that infectious canine hepatitis virus (ICH) and adenoviruses possessed common complement fixing antigens. Heller and Salenstedt ${ }^{2}$ demonstrated five precipitin lines in Ouchterlony plates in the reaction between ICH and convalescent serum from a dog infected with ICH. Three of the antigens forming these precipitin lines were common to adenovirus type 7 which itself gave five precipitin lines with human anti-adenovirus type 7 convalescent serum. The immunological relationship between the two viruses was one-sided, as anti-adenovirus type 7 serum would react in Ouchterlony plates with ICH, but anti-ICH would not react with adenovirus type 7 . Recently, Darbyshire and Pereira ${ }^{3}$ have demonstrated two antigens in the livers of ICH infected dogs which can be precipitated with dog anti-ICH. One of these antigens is precipitated by rabbit anti-adenovirus type 5 serum. In the experiments reported here it was found that ICH infected dog kidney cultures produced only two soluble viral antigens, one of which is closely similar to the $A$ (group specific) antigen of adenoviruses types 5 and 7 and another which is specific for ICH.

Adenovirus type 5 and anti-adenovirus type 5 , which was produced by infecting rabbits with adenovirus type 5 (H.G.P. strain) and used as the $\gamma$-globulin, were obtained from Dr. H. G. Pereira (National Institute for Medical Research, London, N.W.7). Anti-adenovirus type 7. which was hyperimmune serum produced in rabbits, and adenovirus type 7 were obtained from Dr. M. S. Pereira. Virus Reference Laboratory, Central Public Health Laboratory, London, N.W.9.

The adenovirus type 7 was grown on HeLa cells in Parker's Medium No. 199 containing 0.5 per cent lactalbumin hydrolysate. The HeLa cells were propagated in Parker's Medium No. 199 supplemented with 10 per cent fresh calf serum. The adenovirus type 7 used in the experiments contained $10^{7.5} T C D_{50}$ per ml. ICH was grown on primary dog kidney cells. These cells were grown in Hanks's balanced salt solution containing 0.5 per eent lactalbumin hydrolysate, 0.05 per cent bicarbonate and 5 per cent horse serum, and were infected with virus in Parker's Medium No. 199. Tho virus collected was concentrated by ultrafiltration until it contained $10^{8}$ $T C D_{50}$ per ml. Anti-ICH was obtained both from a dog that had been naturally infected with $\mathrm{ICH}$ and from one 